\title{
POR UMA ABORDAGEM DA HISTÓRIA CULTURAL DAS PRÁTICAS DE ESCRITA NA EDIÇÃO DE TEXTOS
}

\author{
FOR AN APPROACH TO THE CULTURAL HISTORY OF \\ WRITING PRACTICES IN TEXT EDITING
}

\section{Patrício Nunes Barreiros}

\author{
Universidade Estadual de Feira de Santana \\ Feira de Santana - BA
}

\section{Resumo}

O artigo discute a mudança de paradigma que ocorreu no campo da História, o surgimento da História Cultural das Práticas de Escrita, os efeitos dessa mudança no âmbito de disciplinas próximas à Filologia, especialmente à Crítica Textual, destacando a interdisciplinaridade como alternativa para inovar e explorar as potencialidades do texto como construto histórico, social, cultural e linguístico. A discussão está fundamentada numa revisão bibliográfica com o intuito de apontar novos caminhos para a edição de textos, considerando a abordagem da História Cultural das Práticas de Escrita. O estudo demonstrou que o diálogo interdisciplinar tem provocado mudanças consideráveis no âmbito da Crítica Textual, ampliando as possibilidades de estudo do texto.

Palavras-chave: Filologia, Crítica Textual, História Cultural.

\section{Abstract}

The present article discusses the paradigm shift that occurred in the History field, the advent of the cultural history of writing practices, the effects this change had on the various disciplines associated to philology, particularly textual criticism, emphasizing interdisciplinarity as an innovative alternative to explore the potentialities of the text as a historical, social and linguistic construct. The discussion is informed by a bibliographical review and aims to highlight new ways for text edition, considering a cultural history of writing practices approach. The study showed that interdisciplinary dialogue has been bringing about significant changes to the scope of textual criticism, thus

\section{Resumen}

El presente artículo discute los cambios de paradigma que ocurrieron en el campo de la historia, el surgimiento de la Historia Cultural de las Prácticas de la Escritura, los efectos de ese cambio en el ámbito de disciplinas próximas a la Filología, especialmente, la Crítica Textual; destacando la interdisciplinaridad como alternativa innovadora para explorar las potencialidades del texto como constructo histórico, social, cultural y lingüístico. La discusión está fundamentada en una revisión bibliográfica con el objetivo de mostrar nuevos caminos para la edición de textos, considerando el tratamiento de la Historia Cultural de las Prácticas Escritas. El estudio demostró que el 
enlarging the possibilities of textual study.

Keywords: Philology, Textual Criticism, Cultural History. diálogo interdisciplinar ha provocado cambios considerables en el ámbito de la Crítica Textual, ampliando las posibilidades de estudio del texto.

Palabras claves: Filología, Crítica

Textual, Historia Cultural.

[...] a idéia de uma produção da sociedade por sistema "escriturístico" não cessou de ter como corolário a convicção de que o público é moldado pelo escrito (verbal ou icônico), torna-se semelhante ao que recebe, enfim, deixase imprimir pelo texto e como o texto que lhe é imposto (DE CERTEAU, 2008: 261).

Na visão antropológica de Michel de Certeau (2008), as práticas escriturísticas correspondem ao ato de imprimir sentidos, assumindo uma função mítica capaz de "inventar" a realidade, no contexto das sociedades modernas. Desse modo, a escrita passa a ter uma força de ação criadora e, como "linguagem fabricada", reflete a sociedade de onde ela nasce e, por sua vez, também representa os sujeitos, suas identidades, sua cultura, ou seja, reflete a imagem do homem e da sociedade.

A escrita alfabética e a sua difusão inscrevem-se entre os acontecimentos mais importantes da humanidade e marcam um salto qualitativo na evolução cultural da sociedade, tornando-se condição imprescindível para se falar da existência de uma civilização desenvolvida e integrada. Segundo Marshall McLuhan (1977: 76, 80),

[...] foi somente pelo alfabeto que os homens destribalizaram ou individualizaram para criar a "civilização". [...] A invenção do alfabeto, à semelhança da invenção da roda, foi a primeira tradução ou redução de um campo complexo e orgânico intercâmbio de espaços num único espaço. $\mathrm{O}$ alfabeto fonético reduziu o uso simultâneo de todos os sentidos, que é a expressão oral, a um código visual (MCLUHAN, 1977: 76).

É quase impossível mencionar um aspecto das sociedades modernas que não tenha nenhuma interferência da escrita. Segundo Pierre Bourdieu (1989), o homem ocidental estruturou sua forma de pensar a partir da lógica da escrita alfabética que se tornou o ponto de convergência para disseminar e equalizar o pensamento, assegurando uma unidade gramatológica padronizada que possibilitou o surgimento da civilização globalizada. 
A escrita é responsável pelo desenvolvimento de práticas sociais que se constituem como a essência das sociedades complexas, possibilitando o registro do cotidiano e, com isso, inventou a noção de homem histórico, capaz de compor um discurso sobre si mesmo. Segundo Michel de Certeau, "[...] nos últimos três séculos, aprender a escrever define a iniciação por excelência em uma sociedade capitalista e conquistadora. É a sua prática iniciática fundamental. [e] [..] uma atividade concreta que tem poder sobre a exterioridade da qual foi previamente isolada" (DE CERTEAU, 2008: 225, 27).

Pensando na relação existente entre as palavras e as coisas, o dito e o não dito, as ideias e suas construçóes no curso da história, Foucault reconheceu o "[...] privilégio absoluto da escrita" nas sociedades ocidentais (FOUCAULT, 2000: 53). Em suas abordagens genealógica e arqueológica da história, Foucault (2008) propôs novos caminhos para abordar a escrita como fonte histórica, entendida por ele como "espaço cinza" a ser iluminado por quem se disponha a devassá-la, não como uma realidade pronta, mas como possibilidades a serem concretizadas a partir das descontinuidades históricas que as envolvem.

Ancorado nessas reflexóes, Michel Foucault (2008) colocou em cheque o papel da história tradicional que se voltava para as fontes textuais como realidades concretas, cabendo aos pesquisadores apenas a função de descrever e interpretá-las (mais descrever que interpretar). Para entender as fontes textuais como resultados de construçôes tecidas nas relaçóes sociais cotidianas, faz-se necessário interpretar as práticas e usos sociais que as "fabricaram". Somente dessa forma, segundo Foucault (2000), é possível adentrar na episteme das fontes textuais como construtos históricos. Nesse sentido, o texto escrito exige uma interpretação histórica desde o primeiro momento de sua existência porque ele é testemunho da experiência humana, forjado no cotidiano e se relaciona com práticas sociais peculiares de sujeitos historicamente constituídos. Esses sujeitos, por sua vez, também se inventam a partir das relaçóes estabelecidas com os textos, entendidos como práticas escriturísticas. Essa é uma questão deveras complexa e diz respeito a todas as disciplinas que adotam o texto escrito como objeto de estudo.

Na busca pela conciliação dessas questóes, Roger Chartier (2005a) propóe, antes de tudo, abordar o texto em sua historicidade primordial, voltando-se para as suas condiçóes de produção, circulação e apropriação. Para Chartier (2001, 2005a), qualquer abordagem do texto que busque compreender os seus significados, precisa vislumbrar suas condiçôes histórica, social e material. Nesse sentido, ele se apoia nas novas perspectivas do campo historiográfico que se abriu para o diálogo com outras disciplinas, favorecendo a constituição de uma história cultural das práticas de escrita e de leitura. Para compreender essas questóes, postas inicialmente por Roger Chartier 
(2002a), cabe investigar como a história ampliou os seus domínios em direção às práticas culturais da escrita, constituindo novos campos de estudos, além do modo como se dá o diálogo entre as disciplinas que têm na escrita o seu objeto de estudo, considerando seus aspectos textual, documental, histórico, social e cultural.

A crise da história e os novos paradigmas para abordar o texto: o diálogo interdisciplinar como alternativa

Segundo Thomas Kuhn (1998), durante o século XX, ocorreram mudanças epistemológicas que se configuraram como uma "crise de paradigmas", provocada pelas transformaçóes advindas dos diferentes setores da sociedade e da exigência de modelos explicativos que pudessem atender às novas problemáticas de um mundo envolvido em constantes transformaçóes. De acordo com Peter Burke (1992), entre as ciências humanas, a história, talvez, tenha sido aquela que mais sofreu o impacto dessa crise e, ao mesmo tempo, foi a disciplina que mais discutiu a crise paradigmática, irradiando inquietaçóes entre as suas vizinhas. A interdisciplinaridade peculiar à história e sua penetração nas humanidades fez com que a crise que se processou na história afetasse as outras disciplinas próximas a ela.

Os novos objetos, problemas e abordagens que foram surgindo entre os historiadores, ao longo do século XX, não mais podiam ser analisados a partir dos pressupostos metodológicos da história política e de cunho nacionalista que orientou a historiografia do século XIX e princípio do século XX (BURKE, 1992). Os historiadores inovaram seus métodos de investigação, levando-os a adotarem posturas interdisciplinares, fazendo uso dos aportes analíticos de outras disciplinas, que contribuíram para a renovação do campo historiográfico e que, por sua vez, também foram influenciadas pela história. Para Tania Regina de Luca (2010), nesse cenário interdisciplinar, tornou-se cada vez mais difícil precisar as fronteiras do campo historiográfico, uma vez que a história praticada nas últimas décadas não é monopólio dos historiadores. $\mathrm{O}$ intenso convívio com as disciplinas vizinhas tem permitido partilhar os mesmos territórios, trazendo inovaçóes e aprendizados simultâneos, constituindo-se no que se convencionou chamar de "virada historiográfica".

A principal característica desse movimento é, pois, o diálogo entre as diferentes áreas, mas é fundamental entender como isso aconteceu. $\mathrm{Na}$ década de 1970, dois dos mais influentes historiadores franceses dos Annales, Jacques Le Goff e Pierre Nora (1978: 11-12), sinalizaram o aparecimento de três novos processos no campo epistemológico da história: "novos problemas" que questionaram o próprio estatuto científico da história; "novas abordagens" que modificaram, enriqueceram e subverteram os setores tradicionais da 
pesquisa historiográfica; e "novos objetos", antes desprezados, passaram a interessar aos historiadores.

Nesse contexto de inovaçóes, surgiu a Nova História que, segundo Peter Burke (1992: 9-10), designa uma prática historiográfica made in France ligada à revista Annales: économies, societés, civilisations, principalmente a sua terceira geração, corresponde à "[...] história escrita como uma reação deliberada contra o 'paradigma' tradicional". Ao lado das transformações sinalizadas pelos historiadores franceses, destaca-se também a renovação do marxismo entre os historiadores ingleses que, a partir da década de 1960, fizeram da New Left Review a porta-voz de suas ideias inovadoras. Segundo Sandra Pesavento (2005: 28), entre os chamados neomarxistas ingleses, Edward Thompson destaca-se por suas críticas ao materialismo histórico e ao estruturalismo, introduzindo inovaçóes nos planos da teoria, do método, da temática e das fontes. Thompson (1987a; 1987b) questionou os estruturalistas, principalmente Louis Althusser, fincando suas raízes numa vertente histórica que se pode chamar de "marxista culturalista".

Em sua obra mais importante, $A$ formação da classe operária inglesa (THOMPSON, 1987a; 1987b), ele analisou o contexto de vida dos trabalhadores, suas inquietaçóes, aspiraçōes, ritos e símbolos coletivos, abrindo novos caminhos às abordagens históricas fora do âmbito francês. De acordo com Peter Burke (1992), é possível sinalizar algumas diferenças fundamentais entre o paradigma tradicional e as novas posturas adotadas pelos pesquisadores da Nova História. No paradigma tradicional, a história era essencialmente política, enquanto os historiadores da Nova História começaram a se interessar por toda a atividade humana, reconhecendo que tudo tem um passado que pode ser interpretado, rompendo a barreira entre o que é central e periférico na história.

Segundo Jacques Le Goff (1999: 109) não basta mais falar dos silêncios da historiografia tradicional. É preciso ir mais longe: “[...] questionar a documentação histórica sobre as lacunas, interrogar-se sobre os esquecimentos, os hiatos, os espaços brancos da história. Devemos fazer o inventário dos arquivos do silêncio, e fazer a história a partir dos documentos e das ausências de documentos" (LE GOFF, 1999: 109). A base filosófica dessa nova perspectiva historiográfica considera que a realidade social é culturalmente constituída (FOUCAULT, 2008; 2009). A história tradicional oferecia uma visão de cima, concentrando-se nos grandes feitos dos grandes homens, relegando o resto da humanidade a um papel secundário na história. Mas a Nova História interessou-se também pela vida ordinária, pela gente "simples", configurandose numa "história vista de baixo" (DE CERTEAU, 2010).

A história tradicional baseava-se em documentos oficias com status de "verdade", em registros escritos emanados do governo. Na Nova História, os 
registros oficiais passaram a expressar apenas um dentre os pontos de vista possíveis da história, por isso os historiadores interessaram-se também por fontes orais, práticas e representaçóes do cotidiano que são interpretadas a partir dos suportes metodológicos de outras disciplinas (BOURDIEU, 1989, CHARTIER, 2002b).

No paradigma tradicional, a narrativa histórica era compreendida como um discurso objetivo, enquanto na Nova História, os pesquisadores começaram a desconfiar da objetividade da narrativa historiográfica, sujeita às mesmas problemáticas do discurso ficcional (WHITE, 1992; VEYNE, 1982; RICOEUR, 2007; DE CERTEAU, 2010).

A terceira geração dos Annales teve como principal estratégia explorar novos territórios, renovando o campo historiográfico, ampliando o seu foco para a cultura, mas ainda se manteve apegada aos pressupostos da história social e econômica, conduzindo suas análises pelo viés marxista, "[...] valorizando a longa duração, a série, o quantitativo, o recorte socioprofissional, aplicados ao estudo das mentalidades" (CHARTIER, 1991: 174-175). Foi nesse contexto que a micro-história italiana surgiu como uma

[...] reação contra um certo estilo de história social que seguia o modelo da história econômica, empregando métodos quantitativos e descrevendo tendências gerais, sem atribuir muita importância à variedade ou à especificidade das culturas locais. [...] Há um paralelo óbvio entre a crítica a essa grande narrativa da história e a crítica ao chamado "cânone" dos grandes escritores [...] enfatizando os valores das culturas regionais e dos acontecimentos locais. [...] Da década de 1970 em diante, foram publicados centenas de estudos micro-históricos, focalizando aldeias e indivíduos [...] (BURKE, 2008: 61-64).

No decorrer da década de 1980, intensificaram-se as críticas em torno da Nova História, principalmente, por ela se pautar numa abordagem social das mentalidades. Essas críticas partiram de dentro mesmo dos Annales, Roger Chartier (1991), por exemplo, censurou duramente a prática historiográfica das mentalidades por considerá-la demasiadamente apegada ao método de investigação das ciências sociais. Para Chartier (2002b, p. 20), o desafio dos historiadores, na década de 1980, foi justamente pensar uma história cultural do social que tomasse como objeto as representaçôes "[...] que, à revelia dos actores sociais, traduzem as suas posiçóes e interesses objectivamente confrontados e que, paralelamente, descrevem a sociedade tal como pensam que ela é, ou gostariam que fosse”. Assim, uma nova prática historiográfica começou a ganhar forma entre os historiadores. Neste sentido, Lynn Hunt (1992: 5-6) observou que:

Nos últimos anos [final da década de 1980], contudo, os próprios modelos de explicação que contribuíram de forma mais significativa para a ascensão 
da história social passaram por uma importante mudança de ênfase, a partir do interesse cada vez maior, tanto dos marxistas quanto dos adeptos dos Annales, pela história da cultura. [...] O mais surpreendente exemplo do desvio dos historiadores marxistas para a cultura é o seu crescente interesse pela linguagem (HUNT, 1992: 6).

A partir de então, os historiadores reduziram a sua escala de observação (inspirados na micro-história italiana) e passaram a privilegiar as apropriaçóes singulares, investigando como cada indivíduo ou comunidade interpreta, em função de sua própria cultura, as ideias e crenças, os textos e as imagens que circulam na sociedade (CHARTIER, 2002b).

Ao concentrar atenção nas linguagens, nas representaçóes e nas práticas sociais, os historiadores começaram a desenvolver uma historiografia, que Lynn Hunt (1992) classificou de "Nova História Cultural". Segundo Peter Burke (2008, p. 68), a palavra "nova" diferencia a Nova História Cultural das formas antigas de fazer história e a palavra "cultural" distingue-a da história intelectual, de longa duração, baseada em ideias e sistemas de pensamentos. Portanto, a Nova História Cultural é um desdobramento da renovação do campo historiográfico que se verificou na década de setenta e da ampliação do foco de análise para uma nova visão de cultura, para além das questóes socioeconômicas.

De acordo com Chartier (2002a: 16-17) a Nova História Cultural "[...] tem como objetivo identificar o modo como em diferentes lugares e momentos uma determinada realidade social é constituída, pensada, dada a ler [...]". As ações simbólicas e as linguagens empregadas na constituição da realidade social de uma comunidade constituem propriamente a sua cultura, que é objeto de interesse da história, mas também de outros campos do saber que se abrigam sobre o amplo "guarda-chuva da nova história cultural". Maria Thereza Negrão de Mello lembra que

[...] a história cultural como espaço de trabalho e campo historiográfico é lugar por excelência de encontros com vizinhos, [...] um espaço de trabalho que tem como pressuposto o diálogo com outras áreas de conhecimento, atravessado que é, no corpus teórico que o define, por noçóes, conceitos e categorias, cuja complexidade rejeita enclausuramentos em território único [...] (MELLO, 2008: 17).

Por conta disso, a Nova História Cultural permite diferentes abordagens, domínios e métodos, variando de acordo com o objeto de estudo, com as fontes utilizadas e com a formação do pesquisador que "[...] nem sempre é um historiador profissional (BURKE, 2008: 176)”. Segundo Susana Guijarro, isso ocorre porque 
Los cultivadores del Nuevo Historicismo no constituyen propiamente una escuela o comparten unánimemente los mismos programas. No ha habido una sistematización de las diferentes prácticas del Nuevo Historicismo en un paradigma. [...] El Nuevo Historicismo se ha constituido en un lugar de intenso debate situado en un cruce de caminos interdisciplinares [...]. Puede decirse que ha incorporado y rechazado elementos de diferentes campos de estudio tradicionales y contemporáneos (GUIJARRO, 1996: 176).

Embora não exista uma unidade entre os praticantes da Nova História Cultural, no que diz respeito aos procedimentos adotados em suas pesquisas, observa-se que algumas temáticas e enfoques são recorrentes. Seguindo esta linha de raciocínio, pode-se dizer que um dos temas mais comuns no campo da Nova História Cultural é a história das práticas de escrita e de leitura (PESAVENTO, 2005: 69). Isso tem acontecido por conta da interdisciplinaridade com que a questão tem sido tratada, envolvendo pesquisadores de diferentes áreas, seja pela diversidade das abordagens e métodos de análises, ou ainda pelo volume de estudos acumulados nessa área, ao longo das últimas décadas.

\section{A história cultural das práticas de escrita}

De acordo com Antonio Castillo Gómez e Carlos Sáez (1994), a história das práticas de escrita e de leitura consiste num desdobramento da história do livro ligada aos historiadores dos Annales que a incluíram entre os seus novos objetos de estudo. O livro de Lucien Febvre e Henri-Jean Martin, publicado em 1958, com o título $O$ aparecimento do livro, fundou a disciplina História do Livro na França, servindo como ponto de partida para uma série de estudos que o sucederam nas décadas precedentes, dando ênfase a questóes sociopolíticas ligadas, principalmente, à alfabetização e ao comércio do livro (CHARTIER, 2005a: 82). Esses primeiros estudos buscaram entender como as ideias eram transmitidas por vias impressas e como o contato com os livros influenciou o pensamento e o comportamento da sociedade. Com o passar do tempo, os historiadores perceberam que o aspecto revolucionário da imprensa não se limitava apenas aos livros, pois,

Quando vemos o que é a produção da imprensa nos séculos XVI ou XVII, vemos que o essencial da produção é constituída, poderíamos dizer, de livros de cordel, panfletos, cartazes, bilhetes, formulários, isto é, todo um conjunto de impressos que não são livros, encomendados por pessoas físicas ou instituiçóes, e que na era do manuscrito não tinha equivalentes. Deste ponto de vista, a importância da imprensa foi produzir de maneira imediata e maciça textos que não são livros e que não existiam ou quase não existiam na era do manuscrito (CHARTIER, 2005a, p. 85). 
A partir desses questionamentos, a história do livro evoluiu para uma história dos impressos e, conforme foi avançando, transformou-se numa história das práticas de escrita e de leitura, porque tanto os livros quanto os impressos não são, nem nunca foram, os únicos suportes da comunicação escrita. Além disso, a escrita e a leitura comportam diversas dimensóes, incluindo tanto o mundo dos impressos quanto o dos manuscritos e dos meios digitais em seus mais variados suportes e usos:

Si aceptamos este punto de vista, que los libros no son la única forma de artefacto textual, sino que hay muchas maneras y formas materiales distintas de textos, sólo algunos de los cuales son libros [...], entonces empezamos a vislumbrar una serie de consecuencias sociales, económicas y políticas [...] (MCKENZIE, 2005: 57).

Trata-se, portanto, de situar o texto numa dimensão ampla dentro da sociedade e de considerar as relaçóes que os sujeitos, alfabetizados ou náo, mantiveram, ao longo do tempo, com o multifacetado mundo da cultura escrita. Neste sentido, Chartier (2001) considera que

[...] a cultura do escrito vai desde o livro ou o jornal impressos até a mais ordinária, a mais cotidiana das produçóes escritas, as notas feitas em um caderno, as cartas enviadas, o escrito para si mesmo, etc. Parece-me que na escrita há um continuum desde a prática da escrita ordinária até a prática da escrita literária (CHARTIER, 2001: 84).

Uma história cultural do escrito abarca as diferentes práticas relacionadas aos meios de produção, circulaçáo e apropriação dos textos por sujeitos sociais e historicamente constituídos. Ao tratar da apropriação do sentido dos textos pelos leitores, espectadores ou ouvintes, Chartier (2009a, 2001) questionou as vertentes teóricas da literatura de tendência estruturalista (nouvelle critique francesa e new criticism norte-americana) que concentram suas análises nos textos em si, independentemente dos objetos e vozes que os transmitem. Sem relacioná-los com a sua materialidade, rejeitando a ideia de que o texto é o resultado de um processo de "fabricação" que envolve autores, editores, tipógrafos, ilustradores, vendedores, distribuidores e leitores em suas singularidades históricas, sociais e culturais. Nesse sentido, Roger Chartier (1991) propóe voltar-se para o mundo do texto e do leitor em busca dos sentidos produzidos pela materialidade da escrita em si, já que os leitores "[...] não se confrontam nunca com textos abstratos ideais, separados de toda materialidade: manejam objetos cujas organizaçóes comandam sua leitura [...]" (CHARTIER, 1991: 179), produzindo sentidos. 

domínios

Ao se aproximar da materialidade dos textos, a Nova História Cultural se deparou com disciplinas que são indispensáveis para a compreensão da forma como os textos são transmitidos, promovendo importantes renovaçóes no âmago da Nova História Cultural e dessas disciplinas. A Paleografia, por exemplo, renovou-se a partir dos estudos empreendidos pelos pesquisadores italianos ligados ao Congresso de Perugia ${ }^{1}$, principalmente das ideias de Armando Petrucci. Segundo Castillo Gómez e Sáez (1999), durante muito tempo, a Paleografia limitou-se a estudar a história da escrita apenas com a finalidade de decifrar o código escrito, atuando como instrumento de

[...] peritación y análisis para la crítica histórica y textual [...], tenía, pues, un carácter eminentemente práctico, y su objetivo estaba en la lectura correcta de los textos. [...] [ou] determinar las características de las distintas escrituras para establecer su identificación y su clasificación, así como su descripción cronológica y geográfica, y la naturaleza del texto. Su trayectoria había respondido con suma precisión al qué, el cuándo, y el cómo de las escrituras (CASTILLO GÓMEZ; SÁEZ, 1999: 24).

A partir da década de 1960, os paleógrafos italianos, fortemente influenciados pelos estudos de orientação marxista e pela renovação historiográfica dos Annales, reorientaram suas práticas de investigação, voltando-se para o social, pois já não bastava

[...] responder al qué, el cómo, el cuándo y el dónde de la escritura, puesto que en este campo prácticamente se habían alcanzado los mejores resultados, sino que era preciso ir más allá de esas preguntas e interrogarse por todo lo concerniente a la función de la escritura y lo escrito - ¿por qué se escribe? — y a la identidad de los escribientes — ¿quién escribe? — En definitiva, la tendencia que nacía en ese momento significaba una "revolución" del tradicional método paleográfico de corte erudito-positivista (CASTILLO GÓMEZ; SÁEZ, 1999: 26).

\footnotetext{
${ }^{1}$ O primeiro congresso de Perugia, convocado pelos paleógrafos Attilio Bartoli Legeli e Armando Petrucci, intitulado Alfabetismo e cultura scritta nella storia della societá italiana. ocorreu em março de 1977 e reuniu especialistas de diversas áreas, para discutirem sobre a escrita e a leitura, a alfabetização e a difusão da cultura a partir da escrita. Um aspecto unia o grupo de pesquisadores envolvidos no congresso: todos eles compartilhavam uma visão marxista da história. Como resultado do congresso de Perugia, o grupo de pesquisadores deu início à publicação da revista sobre cultura escrita: Scrittura e civiltà (1977-2002) e organizaram importantes eventos permanentes como o seminário bianual Alfabetismo e cultura escrita (CASTILLO GÓMEZ; SÁEZ, 1994: 141).
} 
Os paleógrafos passaram a se interessar pela escrita ordinária e pelas diversas formas como a sociedade se relaciona com o mundo da cultura gráfica, ampliando o seu foco de análise para o social, deixando de ser apenas o estudo descontextualizado dos tipos de escrita. Essa Nova Paleografia passou a ser definida

[...] en virtud de la consideración del hecho escrito como un producto sociocultural cuyo estudio e interpretación provee de un conocimiento más rico del pasado y del presente. Esto lleva a interesarse por cualquiera manifestación escrita - documentos, libros, inscripciones, filacterias, grafitos, etc. -, al margen de la época histórica o del soporte material (CATILLO GÓMEZ; SÁEZ, 1999: 26).

A Paleografia expandiu o seu campo de atuaçáo, afirmando-se como uma história das práticas de produção e uso da cultura escrita (PETRUCCI, 1986). É nesse sentido que Antonio Castillo Gómez e Carlos Sáez (1999: 29) afirmam que a renovaçáo da Paleografia transgrediu a tradicional dicotomia entre as ciências da descrição e as ciências da interpretaçáo, superando a diferença entre os objetos e as açóes, optando decididamente por uma reorientação das práticas de pesquisa.

A Diplomática também passou por um processo de renovação, influenciada pelas mudanças ocorridas nas ciências humanas, mas, sobretudo, pelas inovaçôes no campo da história durante o século XX, que passou a considerar o documento como monumento para uma determinada sociedade e cultura. Segundo Jacque Le Goff,

O monumento é um sinal do passado. Atendendo às suas origens filológicas, o monumento é tudo aquilo que pode evocar o passado, perpetuar a recordação, por exemplo, os atos escritos. [...] O monumento tem como características o ligar-se ao poder de perpetuaçáo, voluntária ou involuntária, das sociedades históricas (é um legado à memória coletiva) e o reenviar a testemunhos que só numa parcela mínima são testemunhos escritos (LE GOFF, 1999: 535).

O documento elevado à condição de monumento suscita novos questionamentos para além da classificação tipológica proposta pela Diplomática tradicional. Os documentos são gerados em circunstâncias específicas que determinam a sua materialidade, seu status de prova jurídica e histórica, mas também de produto histórico, social e cultural. Segundo Manuel Romero Tallafigo,

En la segunda mitad del siglo XX la erudita Diplomática tuvo su crisis y salió reforzada con nuevos objetivos, nuevos métodos y nuevos horizontes. De 
ciencia auxiliar de la Historia pasó a ser la trascendental y "pequeña historia" del documento. Éste, desde un análisis más poliédrico con puntos de vista estáticos y dinámicos, se convierte en un estímulo que hace productivos la imaginación y el pensamiento en la reconstrucción y relectura continua del pasado (TALLAFIGO, 2004: 140).

A superação da divisão tradicional entre ciência auxiliar e ciência da interpretação pode ser observada também nos novos rumos da Bibliografia Textual $^{2}$, que foi elevada à condição de "sociologia dos textos" a partir dos estudos do bibliógrafo neozelandês Donald Francis McKenzie e esboçados num ciclo de conferências proferidas em 1985, conhecidas como Panizzi Lectures $^{3}$. As preocupaçôes de Donald McKenzie (2005) circulam em torno do texto (qualquer que seja seu suporte ou forma de registro escrito) e da sua historicidade primordial que, segundo ele, pode ser reconstituída a partir do exame da materialidade da escrita e de seus usos por sujeitos situados numa determinada sociedade. Dessa forma, a sociologia do texto, pensada por Donald McKenzie, ampara-se nas inovaçóes do campo historiográfico e em sua interdisciplinaridade. Para McKenzie (2005, p. 29), os bibliógrafos já não se satisfazem somente com a descrição e com o estabelecimento do texto, pelo método filológico tradicional, eles estão interessados no estudo sóciohistórico que possibilite entender como os textos foram escritos, ganharam forma e foram usados. Ainda segundo Donald McKenzie,

Es aquí, ante todo, donde otras disciplinas como la historia y en especial, la historia cultural está dirigiendo su atención hacia la bibliografía. Lejos de aceptar que "la bibliografía histórica no es, propiamente hablando, bibliografía", es tentador reclamar que hoy toda la bibliografía, propiamente hablando, es bibliografía histórica (MCKENZIE, 2005: 29).

As ideias de Donald McKenzie acerca da sociologia dos textos se encaixaram perfeitamente nas propostas da Nova História Cultural e até mesmo auxiliaram a defini-la. É inegável a grande influência dos estudos de Donald McKenzie nas pesquisas que Roger Chartier (2001) desenvolve no campo da cultura escrita.

O encontro da sociologia dos textos e da história das práticas de leitura e de escrita com a história do livro aconteceu num momento crucial (década de 1980), porque os historiadores estavam redimensionando suas práticas, voltando-se para uma história cultural do social menos apegada às questóes econômicas, concentrando-se nas representaçôes e nas linguagens.

\footnotetext{
${ }^{2} \mathrm{O}$ termo Bibliografia Textual aqui é entendido como o estudo do processo material da produção do livro impresso, com vistas à ediçấo, ou seja, como filologia dos impressos.

${ }^{3}$ As três conferências conhecidas como Panizzi Lectures, foram proferidas em 1985, na British Library, em Londres, com o título Bibliography and Sociology of Texts.
} 
Segundo Peter Burke (2008: 78-79) as práticas e representaçóes são os dois aspectos mais característicos da Nova História Cultural. Por isso, uma sociologia dos textos focada nas práticas culturais da escrita, identificou-se com as propostas da Nova História Cultural. Segundo Robert Darnton (2008, p. 166), a grande novidade da sociologia dos textos foi extrair sentidos das formas como os textos passam a existir numa determinada sociedade, além de relacionar esses sentidos com a história das práticas de escrita e de leitura. Donald McKenzie define a sociologia dos textos como o estudo das

[...] formas registradas [da escrita], así como los procesos de su transmisión, incluyendo su recepción. [...] nos lleva a describir no sólo los procesos técnicos, sino también los procesos sociales de transmisión. [...] se ocupa de los textos no librarios, sus formas materiales, versiones textuales [...] Se refiere a una historia del libro y, de hecho, de todas las formas impresas, incluidos los textos efímeros [...] Porque una historia del libro que excluyera el estudio de las motivaciones sociales, económicas y políticas de la edición, las razones por las que los textos fueron escritos y leídos como lo fueron, y porqué fueron escritos de nuevo y rediseñados, o se dejó que muriesen [...] nunca llegaría a ser una historia que verdaderamente mereciera la pena (MCKENZIE, 2005: 30-31).

Como se pode notar, a abordagem da sociologia dos textos é bastante ampla e dialoga com vários campos do saber, principalmente com a História, a Sociologia e a Crítica Textual. Segundo Chartier (2005b: 6) “[...] las reflexiones de McKenzie han transformado, a su vez, la ciencia bibliográfica (en su definición como bibliografía descriptiva o analítica), la crítica textual y la historia de la lectura".

No que diz respeito à Crítica Textual, Donald McKenzie (2005) questionou a validade de ediçóes que se preocupam unicamente com o estabelecimento do texto e a ideia da supremacia de um testemunho considerado como melhor, digno de ser conhecido, enquanto que os outros entram na categoria de variante, servindo apenas para ratificar o status de verdadeiro de um texto ideal.

McKenzie (2005) critica duramente posturas editoriais que levam em consideração apenas os códigos linguísticos, propondo um novo olhar para a atividade filológica. Nesse sentido, as novas reflexóes em torno do texto, como produto cultural, e as novas abordagens da história provocaram uma reaproximação entre a filologia e a história que assumiram o qualitativo de "nova" para designar as suas práticas na contemporaneidade.

A Filologia, desde os seus primórdios com os alexandrinos do século III a. C.78, sempre foi considerada como uma ciência "[...] eminentemente histórica, que recorre a vários procedimentos e metodologias [...] dedicada a 
indagar e a definir uma cultura [...] através do estudo dos textos" (TELLES, 2000: 95). Entre as diferentes áreas de conhecimento, Segismundo Spina (1994: 81) aponta a História como sendo a disciplina que mantém maior diálogo com a Filologia, afinal de contas, para o seu exercício é necessário, antes de tudo, que exista um passado e os textos como testemunho desse passado. Para Rubio Tovar,

La filología nació bajo el signo de la historia y su objeto era el estudio de los textos. [...] los filólogos dedicados a la crítica textual [no] son ajenos a un enfoque condicionado por el tiempo. La circulación, la transmisión de una obra - manuscrita o impresa - trae consigo errores que pueden enturbiar, cuando no cambiar radicalmente su contendido. [...] la historia es un guía esencial de la filología. [...] Uno de los primeros impulsos que mueven esta etapa de la filología es el de recuperar el legado histórico, reconstruir el pasado partiendo de esa perspectiva arqueológica. [...] El enfoque histórico de la materia tratada informó desde un principio las investigaciones filológicas (RUBIO TOVAR, 2004: 40-41).

O filólogo não é propriamente um historiador, mas ele opera com todos os instrumentos que a história oferece, pois se debruça sobre o texto com o fim de interpretá-lo, de compreender sua relaçáo com a sociedade, com os sujeitos que o manipularam (as mãos que o escreveu, imprimiu, leu, guardou etc.). Ele atua no espaço histórico, não apenas quando lida com o texto, mas, sobretudo quando compóe uma narrativa historiográfica com o objetivo de contextualizá-lo. As introduçóes e tratados sobre a história da transmissão do texto, a contextualização dos meios de produção, circulação e apropriação são exercícios historiográficos empreendidos pelo filólogo.

Diversas áreas de conhecimento dialogam com a filologia, mas a história é indispensável ao seu exercício, pois toda escrita está inserida num passado (longínquo ou imediato). $\mathrm{O}$ ato da escrita é gerido pela lógica do passado, escreve-se porque existe uma continuidade temporal que justifica a necessidade do texto para comunicar algo numa possível ausência. Como disciplina histórica, cabe à filologia compreender a escrita num determinado tempo e isso, naturalmente, implica em conhecer as práticas de produção, circulação e usos dos textos.

Para Fagundes Duarte (2012: 59-65):

A Crítica textual é uma disciplina filológica e por isso, e tendo ainda em conta o sentido geral que actualmente lhe reconhecemos, deve ser encarada como um dos ramos da História, na medida em que se ocupa do processo histórico dos textos em duas vertentes fundamentais: o texto em processo de produção e o texto em processo de transmissão. [A Crítica Textual trata] [...] obrigatoriamente com textos cuja forma e cujo conteúdo foram lá postos 
para serem consumidos por leitores situados, enquanto alocutários, no mesmo estado de língua e no mesmo universo referencial em que se encontrava o agente ilocutário (o autor, [...]). [...] é objeto de estudo da Crítica Textual o estudo dos textos no que diz respeito à sua produção ou à sua transmissão material [...] (DUARTE, 2012: 59-65).

A atividade filológica transcende o ofício do historiador porque, além dos elementos extrínsecos que o texto suscita, volta-se também para o texto como um construto linguístico. Nesse sentido, para Luciana Picchio,

[...] filólogo é quem, utilizando todos os instrumentos dos quais pode dispor, estudando todos os documentos se esforça por penetrar no epistema que decidiu estudar, procurar a voz dos textos e de um passado que já não considera sufocado pelos extratos sobrepostos (PICCHIO, 1979: 234).

A relação entre Filologia e História é observada de forma unânime entre os filólogos, entretanto, vale questionar se essa estrita afinidade mantevese mesmo depois das recentes inovações do campo historiográfico. Talvez essa pergunta possa ser respondida a partir das consideraçóes feitas pelos filólogos ao reconhecerem uma nova fase da Crítica Textual, iniciada desde a década de 1930, classificada por alguns como "Nova Crítica Textual" ou "Nova Filologia" (SPAGGIARI; PERUGI, 2004; PÉREZ PRIEGO, 1997; MCGANN, 1992).

A Crítica Textual como disciplina científica nasceu no século XIX a partir dos estudos do alemão Karl Lachmann e de outros tantos filólogos que se empenharam na ediçâoo de textos bíblicos e dos grandes autores da Antiguidade Clássica. O método lachmaniano (como foi batizado), concentrou-se numa realidade textual cuja busca pelo original perdido foi o seu maior objetivo, instituindo rigor no estabelecimento do texto. Esse método foi influenciado pelas teorias positivistas do século XIX e atendeu às exigências do rigor científico próprios da época. Durante o século XX, o método lachmaniano foi questionado e adaptado às novas realidades textuais, ao lidar com textos autorais. Não se buscava mais o original perdido, mas a recuperação do "ânimo autoral" diante da pluralidade dos testemunhos autógrafos. Mas ainda o que prevaleceu nessa abordagem é a busca pelo estabelecimento do texto, limpo das violaçóes, erros e rasuras, ocorridas no curso da história da transmissão do texto. Esse tipo de postura é incompatível com a renovação das práticas historiográficas, porque ignoram que o texto, qualquer que seja ele (uma cópia ou versão que destoe do original), é testemunho histórico e serve como fonte para entender o modo como o texto foi escrito, difundido e utilizados pelos leitores.

Para Shillingsburg (2004), durante grande parte do século XX, a autenticação do texto representada pelo ânimo autoral foi o princípio 
fundamental que norteou a Crítica Textual. Nesse período não houve grandes discrepâncias entre os filólogos, eles apenas divergiram quanto ao método empregado para o estabelecimento do texto. Todos os esforços do editor residiam em apresentar um texto autorizado, uma "verdade" que emanava de um "texto ideal" e do "ânimo autoral".

$\mathrm{Na}$ Crítica Textual tradicional o que importa é o texto, entendido como a

[...] order of words and punctuation as contained in any one physical form, such as manuscript, proof, or book. A text is the product of the author's, or the author-and-others', physical activity in the attempt to store in tangible form the version the author currently intends [...] That is, the same text can exist simultaneously in the memory in more than one copy or in more than one form. The text is contained and stabilized by the physical form but is not the physical form itself. Each text represents more or less well or completely a version of the work (SHILLINGSBURG, 2004: 46).

Esse modo de compreender o texto favoreceu a elaboração de edições que ignoravam os códigos bibliográficos ${ }^{4}$ e demais documentos consultados pelo filólogo, ao longo da sua pesquisa. O conjunto de informaçôes extralinguísticas e os diversos documentos que se relacionam com o texto, quando agregados à edição, tornam o trabalho muito mais completo. É preciso compreender que o texto não é apenas um código alfanumérico.

Segundo Lucía Megías (2010), documentos paratextuais

[...] no encuentran su lugar en las ediciones críticas tradicionales: Facsímiles, transcripciones (semi)paleográficas de los testimonios base para los estudios linguísticos; presentaciones críticas de los mismos (de manera optativa); intertextos: fuentes textuales de la obra; intratextos: fragmentos de otros textos del autor / época en que aparece el mismo texto editado; y numeroso material de apoyo - tanto iconográfico como sonoro o textual — que se considera pertinente y necesario para la compresión global del texto (LUCÍA MEGÍAS, 2010: 244).

Todos esses documentos são manipulados ou mesmo elaborados pelo filólogo em função do estabelecimento do texto, mas nas ediçóes críticas tradicionais costuma aparecer apenas o texto crítico com um aparato resumido e, às vezes, incompreensível para o leitor. Entretanto, a partir da década de

\footnotetext{
${ }^{4}$ Os códigos bibliográficos são os elementos materiais que garantem a percepção do texto pela visão, dos quais se podem depreender algum sentido. Integram os códigos bibliográficos as dimensōes do papel, a cor da tinta, o tipo de letra, a disposiçấo da mancha sobre a página, as gravuras, o destaque para palavras, a encadernaçáo, os títulos, o layout etc.
} 
1980, intensificaram-se, no âmbito da Crítica Textual, novos interesses e formas de compreender a ediçáo de textos, valorizando a pluralidade de elementos extralinguísticos (MCGANN, 1992). De acordo com Rubio Tovar (2004), nota-se uma reorientação das práticas filológicas desde a década de 1970, já influenciadas pela renovação do campo historiográfico. Mas foi a partir de 1980 que as renovaçôes ganharam força no âmbito da Crítica Textual, influenciadas também por uma disciplina que nasceu dela, a Crítica Genética.

Os textos passaram a interessar aos filólogos, não apenas como códigos alfanuméricos, mas como documentos que consistem "[...] of the physical material, paper and ink, bearing the Configuration of signs that represents a text. Documents have material existence. Each new copy of a text, whether accurate or inaccurate, is a new document". (SHILLINGSBURG, 2004: 47). Essa ideia está em consonância com a visão sociológica de Donald McKenzie ao considerar que:

[...] cualquier versión particular [de um determinado texto] tendrá su propia identidad histórica, no sólo para su autor, sino también para el particular conjunto de lectores que la compraron y la leyeron, [...] Históricamente, puede que no haya razones lógicas para que una versión sea editada por delante de otra. Podemos elegir ésa o aquella por motivos estéticos, pero eso es un problema distinto. [...] La única regla incuestionable parece ser que no debemos hacer una combinación de todas las versiones, puesto que destruiríamos la historicidad de cada una de ellas. [...] Las versiones no son sólo distintas, sino que testimonian un conjunto preciso de significaciones en sucesivos momentos de la historia (MCKENZIE, 2005: 53).

Os erros de impressores, as várias ediçôes e testemunhos, as notas marginais e demais marcas de cada "encarnação" do texto têm uma história que interessa conhecer, principalmente porque revelam o modo como os sujeitos de um determinado tempo se relacionaram com os textos e imprimiram suas marcas neles. Donald McKenzie (2005) propóe considerar cada testemunho em sua potencialidade histórica, porque, segundo ele, cada texto é essencialmente um construto social. Esse modo de pensar ganhou força entre os filólogos na década de 1990, como se pode notar em Miguel Angel Pérez Priego:

Los testimonios son efectivamente individuos históricos, con una fisionomía propia, portadores en su seno muchas veces de elocuentes huellas y datos respecto de dónde se compusieron, quién los cargó o poseyó, quiénes fueron los copistas, los impresores, los lectores, qué tipo de papel y de letra fue utilizado, que taller tipográfico, etc. Todo ello nos proporciona una información muy interesante, por supuesto, para la historia cultural, pero también muy rica y aprovechable desde la validez y agrupación de los testimonios según la información que poseamos, por ejemplo, de la calidad de un determinado 
scriptorium o un taller tipográfico, la procedencia de los originales o copias de que solía servirse, la antigüedad y calidad de los soportes materiales de copia, etc. (PÉREZ PRIEGO, 1997: 36).

A questão posta por Pérez Priego é de ordem histórica, social e cultural, náo se trata de abordar o texto apenas como um construto linguístico, mas como produto da ação humana. Ainda segundo Miguel Angel Pérez Priego (1997), essa nova fase da Crítica Textual

[...] pretende entonces introducir aires nuevos en la rigidez metodológica imperante, romper las cadenas a un tiempo del duro dogmatismo lachamanniano y del simplista escepticismo bedieriano. La propuesta será la de combinar el rigor estemático con el estudio de la historia de la tradición de los textos particulares, individualizando así cada problema. [...] el estudio de la tradición como sustancial a la crítica del texto y no como algo secundario e inconexo. De tal modo los testimonios individuales no serán ya considerados como simples portadores de errores y variantes, sino como productos de una determinada configuración cultural, que es interesante conocer también para la propia crítica textual (PÉREZ PRIEGO, 1997: 15-16).

Essa visão ainda não é compartilhada por todos os filólogos, para muitos deles, a restituição do texto tal como foi idealizado pelo autor com foco apenas nos elementos linguísticos ainda é o único objetivo da Crítica Textual. Nesse sentido, Shillingsburg (2004) esclarece que, no campo da Crítica Textual, existem diferentes abordagens e todas elas são legítimas à medida que mantêm coerência em seus princípios. Ele destaca cinco diferentes abordagens pertinentes na Crítica Textual: "[...] bibliographical, documentary, sociological, authorial, and aesthetic [...]" (SHILLINGSBURG, 2004: 133). Nas três primeiras abordagens, o filólogo pratica a Crítica Textual em diálogo com a sociologia dos textos e a história cultural das práticas de escrita. Nas duas últimas abordagens, a história do texto surge como recurso para o seu estabelecimento, como propóe o método lachmaniano. Para Germán Orduna (2005: 19) uma edição somente pode ser qualificada de crítica quando apresentar um denso estudo da história do texto (evidenciando os processos de produção, circulação e recepção), mesmo quando esse texto oferecer apenas um testemunho.

O debate acerca do estabelecimento do texto, o modo como as variantes são tratadas e a busca da "vontade última do autor" tem gerado polêmicas e ainda divide os filólogos. Mas, nos últimos anos, além das mudanças epistemológicas ocorridas no âmbito das ciências humanas, os avanços da tecnologia no campo da transmissão dos textos também vêm suscitando importantes reflexôes. 
As renovaçóes que se observam na Crítica Textual identificam-se com a Nova História Cultural, quando valoriza o texto em sua historicidade, considerando cada uma das suas "existências", como produtos de uma determinada configuração cultural que têm suas próprias práticas de leitura e de escrita. Dessa forma, concorda-se com Sílvio Elia (1993: 64) quando ele diz que: "[...] o mundo gira e, com ele, as constelaçóes paradigmáticas do céu histórico. [...] [e por isso] cada época tem a sua [...] Crítica Textual.”

Ao considerar os erros de impressão, as variantes e os códigos bibliográficos como produtos da ação humana e importantes elementos que participam dos sentidos do texto, a Crítica Textual amplia seus interesses e avança em direção à Nova História Cultural, à sociologia dos textos, à história das práticas de leitura e de escrita e à História da Cultura Escrita. Para tornar esse diálogo mais profícuo, Miguel Angel Pérez Priego (1997), Jerome McGann (1992) e José Manuel Lucía Megías (2010) sugerem uma prática editorial que respeite as individualidades históricas dos textos, editando, na medida do possível, todos os testemunhos e os elementos paratextuais que possam valorizá-lo como produto da ação humana. Podem-se evidenciar as diversas histórias do texto ao longo de sua existência. Não se trata, portanto, de eliminar os erros de impressores, de escolher uma variante ou reconstituir o original perdido, mas sim de compreender cada uma das marcas impressas no texto, de compreender os testemunhos como portadores de sentidos, inscritos numa materialidade específica e que, por isso mesmo, revelam as formas como os sujeitos históricos se relacionaram com o texto. Editar todos os testemunhos não significa apenas reproduzi-los em fac-símiles, mas explorar suas singularidades históricas, relacionando o texto a outros documentos que podem elucidar melhor a sua sócio-história.

Armando Petrucci (1986, p. 11), ao tratar da reprodução fac-similada pura e simples, sem estar acompanhada de um estudo histórico do texto, fez o seguinte comentário: "[...] Mi rifiuto di essere un paleógrafo di fac-simile, mio lavoro è quello di studiare il testo all'interno della società."

Os significados dos textos não estão apenas nos aspectos alfanuméricos que os transmitem, mas também nos suportes, nas formas materiais que garantem a sua existência, nas relaçôes que mantêm com os seus diferentes testemunhos e nos usos que se fizeram deles ao longo do tempo. Por conta disso, compreender o texto em suas potencialidades de significaçóes implica adotar um método interdisciplinar que concilie, ao mesmo tempo, a Crítica Textual e a história das práticas culturais da escrita (CHARTIER, 2002b: 62). Agindo assim, os filólogos cumprirão sua função transcendente na qual “[...] o texto deixa de ser um fim em si mesmo da tarefa filológica para se transformar num instrumento que permite ao filólogo reconstituir a vida espiritual de um povo ou de uma comunidade em determinada época” (SPINA, 1994: 83). 
Nesse sentido, a Crítica Textual também deixou de ser uma disciplina auxiliar para conquistar seu espaço no campo da interpretação, buscando compreender o texto em seus aspectos sociais, históricos e culturais. Segundo Luciana Picchio,

[...] o filólogo sabe hoje não ser ele um mero preparador de textos a serem entregues depois, prontos para a interpretaçáo, a um pesquisador de grau superior, identificável com o crítico literário. O filólogo sabe desde o início que o seu estatuto é o de crítico, pois nenhuma constituição textual, nenhuma emenda seriam possíveis fora ou antes de uma compreensão total, de uma interpretação no sentido mais amplo e preciso do termo (PICCHIO, 1979: 211-121).

Adotar uma postura crítica diante do texto implica em compreender a sua materialidade, o modo como ele foi lido, as condiçôes políticas e culturais que lhe permitiram chegar aos leitores. Assim, o filólogo deixa de ser um mero preparador de texto para se insurgir como crítico amparado nos seus conhecimentos sobre o texto que é o reflexo da sociedade. Por isso, segundo Chartier (2002b: 62), já não se justifica o raciocínio neoplatônico de que o texto pode apresentar-se como uma entidade cujas diferentes formas não alteram a sua estabilidade linguística e semântica, podendo ser reproduzido sempre igual a si mesmo. Além disso, um texto náo surge de repente, como por geração espontânea, sua existência exige, antes de tudo, a ação de vários atores sociais.

A Filologia estuda o texto como evento cultural e, por conta disso, são muitos os questionamentos que os filólogos podem fazer ao texto, dependendo dos objetivos a que se proponham. No que diz respeito aos impressos, Chartier (2002a: 127) adverte que eles não são propriamente "escritos", mas sim manufaturados, envolvendo vários sujeitos nesse processo: "autores", editores, componedores, tipógrafos, ilustradores, encadernadores etc. Esses sujeitos geralmente não são lembrados, mas tomam decisóes de grande importância e que repercutem no produto final que chega aos leitores.

Os "operários do texto" decidem desde o tipo de letra, a disposição do texto na página, o tipo de papel, a encadernação, a capa e tomam decisóes sobre palavras e trechos. Isso certamente influencia na maneira como os textos serão lidos, apropriados. Desse modo, cada vez que o texto é retomado, seja numa nova edição, seja por meio de uma cópia ou de uma nova leitura, ele se renova ou transcende seus sentidos.

O texto habita um espaço que molda a sua identidade, por isso, toda edição é uma desapropriação, uma desterritorialização. Ao empreender uma edição, transplantando o texto para um novo suporte, alteram-se os códigos bibliográficos e, consequentemente, seus significados mudam, mesmo quando, aparentemente, o texto não muda sua estrutura linguística. Por 
muito tempo, a Crítica Textual esteve preocupada apenas em preservar a unidade do texto, voltando-se apenas para os códigos linguísticos, mas agora é preciso reivindicar também atenção para os códigos bibliográficos, os demais aspectos extralinguísticos que envolvem a materialidade do texto e as demandas sócio-históricas que permeiam os meios de produção, circulação e apropriação dos textos.

Ao dar ênfase a essas questôes, o filólogo não precisa apresentar escusas ou criar novos termos para designar as suas práticas, porque o que ele estará fazendo é propriamente Crítica Textual, afinal de contas, "[...] la filología, entendida como crítica textual, no es un instrumento de la crítica, sino crítica en sí misma" (SÁNCHEZ-PRIETO BORJA, 2003: 113). Mas, para que o filólogo atue como crítico diante do texto é preciso reconhecê-lo como produto cultural e as implicaçóes que isso denota.

Segundo Telles e Santos,

Ao se fazer a opção pela edição de um texto, deve-se levar em conta seu processo de produção e transmissão por meio de seus testemunhos. [...] Tem-se entáo de tecer consideraçóes sobre o suporte de escrita, os instrumentos utilizados para a escrita ou reprodução, por cópia ou impressão, quem escreveu ou reproduziu o texto, o contexto sócio-histórico de produçáo e de reprodução, entre outros aspectos. Estas e outras informaçóes iluminam o texto a ser editado, conjugando o trabalho da Crítica Textual com o de outros campos do conhecimento, ampliando-se as relaçôes, quando necessário, ao estudo e a prática editorial desenvolvidos (TELLES; SANTOS, 2012: 65-66).

O estabelecimento do texto continua sendo válido, legítimo e necessário, mas ele não deve ser um fim em si mesmo. Os elementos paratextuais e prototextuais que integram os dossiês dos textos precisam aparecer para os leitores porque eles reúnem valiosas informaçóes que podem enriquecer a sua leitura. Não se pretende diminuir o mérito das práticas de edição mais tradicionais, mas sim ampliar os horizontes da atuação filológica, fomentando o diálogo interdisciplinar.

\section{À guisa de conclusão}

Durante muito tempo, a Crítica Textual manteve uma relação estrita com a linguística e a literatura, concentrando suas análises críticas apenas nos aspectos que interessavam a essas duas disciplinas (abordando o texto apenas nos seus aspectos linguístico e literário), mas agora é preciso ampliar a abordagem filológica para o diálogo interdisciplinar mais amplo, para uma compreensão do texto como produto cultural e histórico complexo. Nesse sentido, a Nova História Cultural trouxe inúmeras contribuiçóes para o campo 
da Crítica Textual, ao dar ênfase às singularidades do texto pelo estudo das práticas de escrita e de leitura. Esse modo de fazer história vislumbra o texto como produto cultural e, por isso, tornou-se um ponto de convergência para várias disciplinas que se dedicam ao estudo do texto.

A crise dos paradigmas e os novos diálogos que estão se processando entre as ciências humanas têm favorecido uma nova visão de Crítica Textual. A relevância da escrita nos estudos históricos e os desdobramentos da crise dos paradigmas, durante o século XX, contribuíram para a constituição de uma disciplina que tem se destacado, no âmbito acadêmico, pelo seu caráter interdisciplinar. Trata-se da História da Cultura Escrita que, segundo Antônio Castillo Gómez,

[...] se define por el alcance de sus enunciados y por la interdisciplinaridad de un método que debe buscar las alianzas con cuantos saberes tienen su objeto en el estudio de la escritura. Una propuesta, en consecuencia, que viene a superar la distinción convencional entre la historia de la escritura, por un lado y la historia del libro y de la lectura, por otro, para hacerlas convergir en un espacio común: el de la historia social de cultura escrita, cuyo cometido sería el estudio de la producción, difusión, uso y conservación de los objetos escritos, cualquiera que sea su concreta materialidad - del documento oficial a la carta privada - o soporte — de la tablilla de arcila a la pantalla electrónica (CASTILLO GÓMEZ, 2001: 19-20).

Observa-se que os objetivos da História da Cultura Escrita transcendem uma concepçáo de escrita como um mero sistema gráfico, ela adquire valor como categoria de análise histórica cujo estudo deve atender às consequências sociais e culturais derivadas da implantação e extensão do código escrito. Desse modo, a escrita passa a ser compreendida em suas diferentes funçóes e consequentes práticas materiais e usos, sempre em referência às respectivas sociedades históricas com suas peculiaridades. De acordo com Castillo Gómez (2003), a História da Cultura Escrita busca

[...] saber por qué razones se ha hecho uso de la escritura en cada momento y sociedad, conocer la distribución de las capacidades de escribir y de leer, las materialidades de lo escrito, y los distintos lugares, espacios y maneras en los que se ha experimentado su recepción, en fin, las prácticas de la escritura y de la lectura, es una forma de hacer historia cultural. Entendida así, la cultura escrita pone de manifiesto la rica gama de sus matices y se configura como un espacio de investigación abierto al diálogo interdisciplinar. [...] la historia de la cultura escrita se distingue de otras formas de practicar la historia cultural por la valorización que otorga al análisis morfológico de los productos escritos. Una especificidad que reserva un papel destacado a las disciplinas eruditas pues son éstas las que poseen las herramientas conceptuales más adecuadas 
para el examen de las formas materiales de los objetos escritos. En definitiva, la historia de la cultura escrita constituye un nuevo espacio científico para dichas materias, pero esto no debe confundirse con la equiparación de sus objetos y métodos de estudio (CASTILLO GÓMEZ, 2003: 96, 108-109).

Nota-se que, nas últimas décadas, processou-se um verdadeiro boom dos domínios da história que, a partir de 1970, se viu ameaçada pela crise dos paradigmas. A história se revigorou, tornando-se nova e cultural, focada nas práticas e no cotidiano, ampliou seus horizontes em direção a outras ciências com as quais aprendeu e ensinou.

O resultado de tudo isso é positivo, porque, afinal de contas, todos saem ganhando (historiadores, sociólogos, antropólogos, filólogos etc.). Há de se reconhecer que as intensas reflexóes que ocorreram no âmbito da história, modificaram de forma significativa a compreensão das dimensóes sociais, culturais e históricas da escrita. Isso evidenciou a importância de se compreender a historicidade primordial do texto e vem reorientando as pesquisas para uma história cultural de suas práticas.

As reflexões e inovaçóes dos domínios da história, principalmente, a partir da Nova História Cultural, favoreceram a renovação da Paleografia, da Bibliografia Textual, da Diplomática, da Crítica Textual, o surgimento da História da Cultura Escrita e uma abordagem do texto que considere as práticas, entendida como História Cultural das Práticas de Escrita. Esses campos do saber revitalizaram-se à medida que passaram a admitir a necessidade dos diálogos interdisciplinares patrocinados pelo fim das disputas por territórios e da demarcação de fronteiras rígidas.

Referências bibliográficas

BOURDIEU, Pierre. O poder simbólico. Tradução de Fernando Tomaz. 5. ed. Rio de Janeiro: Difel, 1989.

BURKE, Peter. (Org.). A escrita da História: novas perspectivas. Tradução de Magda Lopes. São Paulo: UNESP, 1992.

CASTILLO GÓMES, Antonio (Coord.). Historia de la cultura escrita: del próximo oriente antiguo a la sociedad informatizada. Espańa: Trea, 2001.

CASTILLO GÓMEZ, Antonio; SÁEZ, Carlos. Paleografía versus alfabetización. Reflexiones sobre historia social de la cultura escrita. Signo. Revista de Historia de la Cultura Escrita, n. 1, 1994, p. 133-168.

CASTILLO GÓMEZ, Antonio. Historia de la cultura escrita: ideas para el debate. Revista Brasileira de História da Educação, n. 5, 2003, p. 93-124. 
CASTILLO GÓMEZ, Antonio; SAEZ, Carlos. Introducción a la Paleografía y la Diplomática General. Madrid: Síntesis, 1999.

CHARTIER, Roger. O mundo como representação. Estudos Avançados, São Paulo, v.5, n.11, 1991.

CHARTIER, Roger. Cultura escrita, literatura e história: Conversas de Roger Chartier com Carlos Aguirre Anaya, Jesús Anaya Rosique, Daniel Goldin e Antônio Saborit. Porto Alegre: Artmed, 2001.

CHARTIER, Roger. Entre práticas e representaçóes. Tradução de Maria Manuela Gafhardo. 2. ed. São Paulo: DIFEL, 2002a.

CHARTIER, Roger. Os desafios da escrita. Tradução de Fulvia M. L. Moretto. São Paulo: UNESP, 2002b.

CHARTIER, Roger. Da história da cultura impressa à história cultural do impresso. Revista Brasileira de Ciências da Comunicação, São Paulo, v. 28, n. 1, 2005.

CHARTIER, Roger. A história ou a leitura do tempo. Tradução de Cristina Antunes. Belo Horizonte: Autêntica, 2009.

DARNTON, Robert. O que é a história do livro?. Tradução de Lília Gonçalves Magalhães Tavolaro. ArtCultura, Uberlândia, v. 10, n.16, 2008, p. 155-169.

DE CERTEAU, Michel. A invenção do cotidiano. 1. Artes de fazer. Tradução de Ephraim Ferreira Alves. 15. ed. Petrópolis: Vozes, 2008.

DE CERTEAU, Michel. A escrita da história. Tradução de Maria de Lourdes Menezes. 2. ed. Rio de Janeiro: Forense Universitária, 2010.

DUARTE, Luiz Fagundes. Entre Penélope e Euriclea. In: TELLES, Célia Marques. SANTOS, Rosa Borges dos. (Org.). Filologia, críticas e processos de criação. Curitiba: Appris, 2012, p. 53-67.

ELIA, Sílvio. A crítica textual em seu contexto sócio-histórico. In: ENCONTRO DE ECDÓTICA E CRÍTICA GENÉTICA, 3; Anais... João Pessoa: UFPB/ APML / FECPB / FCJA, 1993, p. 57-64.

FOUCAULT, Michel. Ditos e Escritos: arqueologia das ciências e história dos sistemas de pensamento. Rio de Janeiro: Forense Universitária, 2002. Vol. II.

FOUCAULT, Michel. A arqueologia do saber. Tradução de Luiz Felipe Baeta Neves. 7. ed. Rio de Janeiro: Forense Universitária, 2008.

FOUCAULT, Michel. A Ordem do discurso. Tradução de Laura Fraga de Almeida Sampaio. 18. ed. São Paulo: Loyola, 2009.

GUIJARRO, Susana. La historia cultural: tendencias y nuevas perspectivas en la historiografía angloamericana. Signo Revista de Historia de la Cultura Escrita, Alcalá de Henares, Universidad de Alcalá de Henares, n. 3, 1996, p. 163-191. 
HUNT, Lyann. A história cultural. Tradução de Jefferson Luiz Camargo. São Paulo: Martins Fontes, 1992.

KUHN, Thomas S. A estrutura das revoluçóes científicas. Tradução de Beatriz Vianna Boeira e Nelson Boeira. 5 ed. Sáo Paulo: Perspectiva, 1998.

LE GOFF, Jacques. História e memória. Tradução de Irene Ferreira, Bernardo Leitão e Suzana Ferreira Borges. Campinas: UNICAMP, 1999.

LE GOFF, Jacques; NORA, Pierre. História: novos problemas. Tradução de Théo Santiago. Rio de Janeiro: Francisco Alves, 1978.

LUCA, Tania Regina. Historia dos, nos e por meios dos periódicos. In: PINSKY, Carla Bassanezi. (Org.). Fontes históricas. 2. ed. São Paulo: Contexto, 2010.

LUCÍA MEGÍAS, José Manuel. Reflexiones en torno a las plataformas de edición digital: el ejemplo de la Celestina. In: POALINI, Devid. (Coord.). De ninguna cosa es alegre posesión sin compañia, estudios celestinescos y medievales en honor del profesor Joseph Thomas Snow. Tomo I. New York: Seminário Hispánico de Estudios Medievales, 2010, p. 226-251.

MCGANN, Jerome. A critique of modern textual criticism. 5. ed. Chicago: University of Chicago Press, 1992.

MCKENZIE, Donald Francis. Bibliografía y sociología de los textos. Madrid: Akal, 2005.

MCLUHAN, Marshall. A galáxia de Gutemberg, a formação do homem tipográfico. Tradução de Leônidas Gontijo de Carvalho e Anísio Teixeira. 2 ed. São Paulo: Nacional, 1977.

MELLO, Maria Thereza Negrão de. História cultural como espaço de trabalho. In: KUYUMJIAN, Marcia de Melo M.; MELLO, Maria Thereza Negrão de. (Org.). 2008. Os espaços da história cultural. Brasília: Paralelo 15, 2008.

PÉREZ PRIEGO, Miguel Angel. La Edición de textos. Madrid: Síntesis, 1997.

PESAVENTO, Sandra Jatahy. História e história cultural. 2. ed. Belo Horizonte: Autêntica, 2005.

PETRUCCI, Armando. La scrittura: ideologia e rappresentazione. Torino: Einaudi, 1986.

PICCHIO, Luciana Stegagno. A lição do texto: filologia e literatura. Tradução de Alberto Pimenta. Lisboa: Ediçốes 70, 1979.

RICOEUR, Paul. Tempo e narrativa. Tradução de Marcondes Cesar. Campinas: Papirus, 1994.

RICOEUR, Paul. A memória, a história, o esquecimento. Tradução Alain François [et al.]. Campinas: Editora da Unicamp, 2007. 
RUBIO TOVAR, Joaquim. La vieja diosa: de la filología a la posmoderindad. Madrid: Centro de Estudios Cervantinos, 2004.

SÁNCHEZ-PRIETO BORJA, Pedro. Nuevas posibilidades y nuevas exigencias de la crítica textual: la "lectura asistida". Letras de Deusto, v. 33, n. 100, 2003.

SHILLINGSBURG, Peter L. Scholarly editing in the computer age: theory and practice. 3. ed. Michigan: University Michigan, 2004.

SPAGGIARI, Barbara; PERUGI, Maurizio. Fundamentos de Critica Textual. Rio de Janeiro: Lucerna, 2004.

SPINA, Segismundo. Introdução à edótica: crítica textual. 2. ed. rev. e atual. São Paulo: Ars Poetica/EDUSP, 1994.

TALLAFIGO, Manuel Romero. Archivistica y archivos: soportes, edificios y organización. 2. reimp. Madrid: S\&C, 2002.

TALLAFIGO, Manuel Romero. Nueva diplomática, nueva metodologia para la historia del documento. Signo, Revista de historia de la cultura escrita, Madrid, n. 14, 2004, p.139-183.

TELLES, Célia Marques; SANTOS, Rosa Borges dos. (Org.). Filologia, criticas e processos de criação. Curitiba: Appris, 2012.

THOMPSON, Edward. A formação da classe operária inglesa. v. 1. Rio de Janeiro: Paz e Terra, 1987a.

THOMPSON, Edward. A formação da classe operária inglesa. v. 2. Rio de Janeiro: Paz e Terra, 1987b.

WHITE, Hayden. A Meta História. São Paulo: EDUSP, 1992.

Patrício Nunes Barreiros. Professor Adjunto na Universidade Estadual de Feira de Santana. Doutor em Letras e Linguística pela UFBA (2013). Desenvolve pesquisa nas áreas de crítica textual, acervos de escritores e humanidades digitais.

E-mail: patriciobarreiros@hotmail.com 